\title{
Research on Teaching Reform of Computer Specialty Under the Background of IEET Project Certification
}

\author{
Ju-bao QU*, Hong-tao LIANG and Xiao-fei LI \\ School of Mathematics and Computer, Wuyi University, Wuyishan, Fujian, China \\ ${ }^{*}$ Corresponding author
}

Keywords: IEET; Engineering Accreditation; Computer Specialty; Teaching Reform.

\begin{abstract}
According to the current situation of computer specialty in our university, this paper analyzes the similarities and differences between the current training program of computer specialty and IEET standard, and puts forward the idea of changing teachers' traditional teaching to "double-qualified" teachers around the eight core competencies of computer science and technology specialty under IEET standard. A series of measures such as increasing the proportion of practical teaching, changing practice links for engineering training and so on had been put forward. It is proved that the reform of the teaching scheme of computer specialty is effective and feasible by the IEET expert on-the-spot investigation and certification.
\end{abstract}

\section{Introduction}

Institute of Engineering Education Taiwan (Abbreviation IEET) started the certification of Engineering Education in 2004. IEET is one of the three major professional appraisal institutions in Taiwan to assess whether the accredited courses or institutions meet the academic or professional standards of the accredited institutions [1]. IEET has participated in many international certification agreements, such as the Washington Accord. It has internationally recognized qualifications in professional certification and has a very rich practical experience. The computer science and technology speciality of Wuyi college began to receive IEET professional certification in 2016 [2]. Compared with the IEET professional certification evaluation index system, it is quite different from the traditional education in terms of training objectives, graduation requirements, curriculum system, teaching evaluation methods, etc. It is necessary to make corresponding adjustments to the existing professional training programs, curriculum teaching and other aspects, and establish a good teaching evaluation mechanism to ensure that the quality of computer professional training is based on internationalization.

\section{Difference between IEET Standard and Our Current Computer Professional Training Objectives}

The training objectives of Chinese majors are determined by the needs of the state, society and education, in accordance with the requirements of industry development and the workplace, the orientation and development goals of schools, the development of students and the expectations of parents and alumni. The formulation of the training program should be through the establishment of an advisory committee to absorb the participation of industries, enterprises, universities and other parties [3]. A closed-loop feedback system is formed between the major training objectives, graduation requirements and curriculum system under the IEET engineering certification standard. First of all, from the perspective of schools and specialties, schools and specialties set training objectives for talents to be trained, and then formulate core competencies in accordance with the training objectives, and then construct relevant courses according to core competencies. Curriculum and teaching help students cultivate core competencies, and then examine students' learning outcomes with various evaluation methods [4]. Finally, the connotation of the training objectives is feedback through the evaluation results, and the training objectives are modified and adjusted accordingly. This series of processes form a feedback loop, through which the continuous cycle makes the professional 
training objectives and core competencies more perfect and better fit.

\section{Eight Core Competencies of Computer Science and Technology under IEET Specification}

According to IEET Engineering Certification Standard, students majoring in computer science and technology should have eight core competencies after graduation: (1) the ability to apply mathematics, science and engineering knowledge; (2) the ability to design and execute experiments, as well as the ability to analyze and interpret data; (3) the ability to execute computer software design, application development, system integration, and maintenance. Management, training and teaching of computer engineering practices required technology, skills and the ability to use modern tools; (4) hardware systems, application development, system integration applications, such as analysis, design capabilities; (5) computer system project management (including budget planning and cost budgeting), effective communication, domain integration and teamwork capabilities (6) the ability to discover, analyze and apply research results in computer science and technology-related fields and to deal with complex and comprehensive engineering problems; (7) the ability to understand the situation at home and abroad and the frontier information of computer science and technology disciplines, to be familiar with the impact of computer science and technology on the environment, society and the world, and to foster sustained development Learning habits and abilities; (8) Humanities and social science literacy and social responsibility, understanding and application of professional ethics and respect for multiple perspectives.

It is not difficult to see from this core competence that the training objectives of students are different from the traditional teaching objectives, and they are more inclined to the training, application and teamwork of engineering competence. This requires that teachers should neither blindly inculcate knowledge, nor completely interfere with it, but design short-term or team-work for students as a guide. Long-term learning goals, to encourage students to find ways and means to achieve the goal, require that theoretical knowledge not only have breadth but also depth, and have the ability to solve problems.

\section{Reform the Traditional Teaching Idea of Teachers}

IEET standards require students as the main body, students' training objectives are different from the traditional teaching objectives, more inclined to engineering ability training, application and teamwork, which requires teachers to neither blindly indoctrinate knowledge, nor completely non-interference, but as a guide for students to design short-term or long-term Learning objectives, encouraging students to find ways and means to achieve the goal, requires that theoretical knowledge not only have breadth but also depth, and have the ability to solve problems.

\section{Change to "Double Qualified" Teachers}

According to IEET standard, teachers should not only have good professional experience, but also have rich teaching experience of "double-qualified" teachers, so as to be more conducive to combining theory with practice, so that students can grow up rapidly in the teaching of integration of theory and practice. But for a while, there are few "double qualified" teachers, which requires schools to be introduced and sent together. On the one hand, the introduction of relevant industry experience "insiders" to supplement the teaching team, on the other hand, through the deployment of enterprise science and technology commissioners to the relevant enterprises and other forms, to strengthen the existing teachers and related enterprises, enhance the professional experience and practical ability of teachers. The development of the "double qualification" of teachers has provided a strong guarantee for the improvement of students' practical ability.

\section{Adjusting the Proportion between Practice Teaching and Theoretical Teaching}

According to the IEET standard, students should complete more practical skills training and 
practical engineering operation during the school period to shorten the period of adaptation after employment, which requires the computer professional training program to increase experimental hours and reduce theoretical teaching hours. It is required that we can not only teach the overall structure and working principle of the computer system from the global or macroscopic point of view, but also understand the working process and interaction mode of each component of the computer from the local or microscopic point of view.

\section{Reform Practice is Engineering Training}

IEET certification attaches great importance to practical teaching, especially engineering training, to enterprises to participate in hands-on ability training. If we simply teach students how to use the experimental box for practical teaching, it is bound to restrict the cultivation of students' open thinking. With the development of electronic design automation (EDA) technology, system simulation technology is becoming more and more perfect. In view of the generally accepted standard of talent cultivation ability in the electronic design industry, it is necessary to strengthen the training of students' EDA skills. If the former manual design, welding, installation, and then debugging using oscilloscopes are still the main engineering. The traditional method of design is to train students, the consequence is that the students can not meet the needs of society. Modern engineering design, especially in the fields of computer and communication, EDA technology is the core and key. Simulation, simulation and virtual design are the main design means and development trend. This new technology is introduced into the experiment. Teaching is absolutely necessary.

\section{Adopting Multi Level Experimental Teaching}

IEET authentication links more emphasis on personalization, stratification and secondary teaching. According to students' ability, teaching can be carried out in different levels: basic experiment, open experiment, comprehensive experiment and research experiment. The basic experiment is carried out to further deepen the students' understanding of the theoretical knowledge in accordance with the theoretical teaching content, and can be set up in ordinary experiments; the open experiment is to further improve the teaching level, cultivate students' experimental skills, and let students understand the advanced technical progress of this course, which can be borrowed from the school. Network teaching platform to open the experiment; and comprehensive experiment in order to develop students' design ability and ability to analyze and solve problems, can be set up in the curriculum design; research experiment is a higher level requirement, is to cultivate students' innovative thinking and research ability, can arrange innovative entrepreneurship experiment projects. Teacher research and graduation design. In order to achieve the combination of theory and practice, we can cultivate useful talents who understand theory, practice and innovate.

\section{Analysis of Reform Effect}

The computer science and technology speciality of our college took part in IEET certification in 2017.

Table 1. Summary of the 2017 Student Capstone Curriculum Achievement

\begin{tabular}{llllll}
\hline Equal grades & Excellent & Good & Secondary & Pass & Fail \\
\hline Student number & 10 & 50 & 44 & 0 & 0 \\
Proportion & $9.62 \%$ & $48.08 \%$ & $42.31 \%$ & $0.00 \%$ & $0.00 \%$ \\
\hline
\end{tabular}

With the joint efforts of all the teachers and students in this major, they have passed the IEET engineering certification with excellent results. One of the core certification courses, Capstone, takes into account students' comprehensive abilities best. Table 1 shows the overall performance of the students in the course. Capstone's course performance consists of three parts: the supervisor's 
assessment, the two reviewers' assessment of the project report and the project defense. As can be seen from table 1 , the results are mainly distributed in good times.

\section{Conclusion}

IEET certification has been globalized. Engineering education certification is an inevitable trend for engineering majors to promote professional development, improve the quality of personnel training, enhance the adaptability of talent industry, and enter the international talent market. Therefore, this paper analyzes the similarities and differences between the IEET standard and the current training objectives of computer specialty in China, compares the eight core competencies of computer science and Technology Specialty under the IEET standard, and puts forward the idea of changing teachers' traditional teaching to "double-qualified" teachers. A series of measures have been taken, such as adjusting the proportion of practical teaching and theoretical teaching, reforming the practice links into engineering practice. Finally, through the IEET experts' on-site certification and high passing rate, it has been proved that the teaching reform of computer specialty is successful and has certain popularization value.

\section{Acknowledgments}

This research was financially supported by The Key Laboratory of Cognitive computing and intelligent information processing of Fujian Education Innovation, Fujian Provincial Higher Education Innovation and Entrepreneurship Education Reform Project (sjzy2017002), Fujian Provincial University "Curriculum Thought" Education and Teaching Reform Project (KC18087), Fujian Provincial Natural Science Foundation Project (2017J01406).

\section{References}

[1] Lu Guiping, Cui Ning, Xian Hualong, Zheng Jinhui. Research on the Cultivation of College Students'Innovative Design Ability Based on IEET Engineering Education Certification [J]. Education Modernization, 2017 (4): 1-5.

[2] Chen Guotie, Wang Jian. The status quo and Enlightenment of IEET engineering education certification in Taiwan [J]. China Construction Education, 2014 (1): 50-54.

[3] Hu Wenlong. Teaching Development of College Teachers under the Background of Engineering Professional Certification [J]. Research on Higher Engineering Education, 2015 (1): 73-78.

[4] Shi Zhenghao, Zhao Minghua, Li Peng, Wang Yinghui. Exploration and Practice in Teaching Reform of Computer Composition and Architecture Course [J]. Teaching Research, 2013 (2): 64-67. 